\title{
IMPLEMENTASI MODEL WATERFALL PADA SISTEM INFORMASI PERSEDIAAN BARANG BERBASIS WEB (STUDI KASUS: PT.PAMINDO TIGA T)
}

\author{
Fatmawati $^{1}$, Jajat Munajat ${ }^{1}$ \\ ${ }^{1}$ Program Studi Sistem Informasi, STMIK Nusa Mandiri Jakarta, Indonesia \\ ${ }^{1}$ Jln. Damai No.8, Warung Jati Barat (Margasatwa), Jakarta Selatan, Indonesia
}

\begin{abstract}
Abstrak
PT. Pamindo Tiga T saat ini dalam proses persediaan barang masih dilakukan secara manual karena masih menggunakan pencatatan di buku dan microsoft excel, seperti input barang masuk dan input barang keluar. Sehingga informasi yang diterima oleh pihak yang terkait sangat susah didapatkan secara cepat. PT. Pamindo Tiga T yang bergerak di bidang manufaktur yang memproduksi komponen kendaraan roda dua dan roda empat sangat membutuhkan sistem informasi yang lebih mudah dan cepat agar dapat menunjang kebutuhan operasional perusahaan. Berdasarkan hasil analisa pada penelitian ini penulis menggunakan Metode SDLC dengan model waterfall sedangkan tool yang digunakan berupa ERD (Entity Relationship Diagram) dan UML (United Modelling languange) dan dengan adanya sistem informasi persediaan barang berbasis web ini dapat lebih mudah dalam mendapatkan informasi terbaru, serta mempermudah dalam pengolahan data barang masuk dan barang keluar.
\end{abstract}

Kata kunci: Sistem Informasi Persediaan, Waterfall, ERD, UML, Web

\begin{abstract}
PT. Pamindo Tiga T is currently in the inventory process is still done manually because it still uses bookkeeping and microsoft excel, such as inputs of incoming goods and input of goods out. So the information received by the relevant parties is very difficult to get quickly. PT.Pamindo Tiga $\mathrm{T}$ which is engaged in manufacturing that produces two-wheeled and four-wheeled vehicles requires information systems that are easier and faster in order to support the needs of the company's operations. Based on the results of the analysis in this study the authors use SDLC method with waterfall model while the tool used is ERD (Entity Relationship Diagram) and UML (United Modeling languange) and with this web-based inventory information system can be easier in getting the latest information, as well as simplify the processing of data $b$ incoming and outgoing goods .
\end{abstract}

Keywords : Inventory Information System, Waterfall, ERD, UML, Web.

\section{PENDAHULUAN}

PT. Pamindo Tiga T saat ini masih menggunakan sistem manual dalam proses pencatatan barang masuk dan barang keluar, dalam proses bisnisnya bagian gudang melakukan pencatatan setiap kali ada barang masuk yang dilengkapi dengan surat jalan serta tanda bukti transaksi dan juga ketika barang keluar dari gudang, stock dicatat secara manual dibuku, yang kemudian direkap dan diinput pada microsoft excel untuk laporan data stock barang tiap bulannya, adapun kendala yang terjadi adalah sulitnya dalam pencarian stok barang serta pengolahan data.

Berikut ini penelitian terkait mengenai sistem informasi persediaan barang. Dalam penelitian yang berjudul Rancang Bangun Sistem Informasi Inventory Barang Berbasis Web Studi Kasus di PT. Infinetworks Global Jakarta, masalah yang terdapat pada penelitian ini adalah proses pencatatan barang masih dilakukan secara manual dan masih menggunakan spreadsheet sebagai alat bantu dan kerap terjadi kehilangan data barang dan keterlambatan dalam penyusunan inventory barang. Metode yang digunakan dalam penelitian ini adalah studi kepustakaan, dokumentasi, wawancara, observasi serta analisis dan desain dengan menggunakan UML (United Modelling languange) dan tahap pengembanagan berdasarkan metode berorientasi objek. Hasil dari penelitian tersebut yaitu dapat mempercepat proses pengolahan data dan dapat mengatasi kelemahan pada sistem yang masih manual serta dapat menmempermudah dalam pencarian data yang dibutuhkan[1].

Identifikasi permasalahan yang ada pada PT. Pamindo Tiga T dalam penelitian ini adalah:

1. Proses penerimaan dan pengeluaran barang digudang memerlukan waktu yang relatif lama karena ditentukan oleh ketelitian bagian gudang itu sendiri.

2. Tidak terdapat penyimpanan data berbasis database, sehingga pengolahan dan pencarian data barang menjadi lama.

3. Lambatnya proses pengolahan data, sehingga data dan informasi yang dihasilkan kurang akurat

Berdasarkan permasalahan yang ada, maka maksud dari penelitian ini adalah penulis membuatkan sebuah aplikasi sistem informasi persediaan barang berbasis web untuk mempermudah perusahaan dalam penginputan data barang masuk dan barang keluar serta mempermudah dan mempercepat dalam pencarian stok barang. 


\section{TEORITIS}

\subsection{Sistem Informasi}

Sistem informasi (information system) merupakan kombinasi teratur dari orang-orang, perangkat keras, perangkat lunak, jaringan komunikasi, dan sumber daya data yang mengumpulkan, mengubah, menyebarkan informasi dalam sebuah organisasi[2].

\subsection{Persediaan}

Persediaan dapat diartikan sebagai barang-barang yang disimpan untuk digunakan atau dijual pada masa atau periode yang akan datang. Persediaan terdiri dari persediaan bahan baku, persediaan barang setengah jadi dan persediaan barang jadi[3].

\subsection{Waterfalll}

Pengembangan perangkat lunak menggunakan metode waterfall memiliki lima tahapan sebagai berikut:

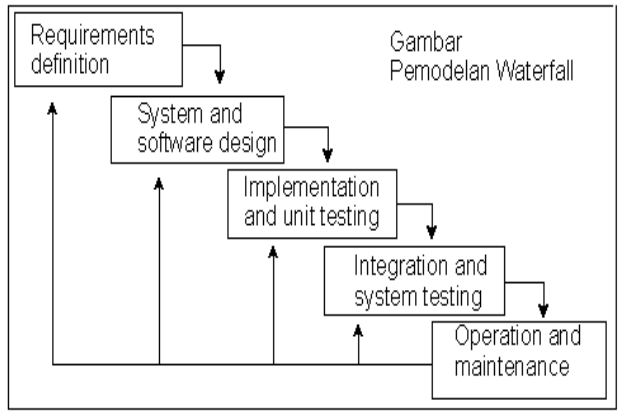

Gambar 1. Perangkat Lunak Waterfall

1. Definisi Kebutuhan (Requirement Analisys Definition)

Merupakan tahapan penetapan fitur, kendala dan tujuan sistem melalui konsultasi dengan pengguna sistem. Semua hal tersebut akan ditetapkan secara rinci dan berfungsi sebagai spesifikasi sistem.

2. Desain Sistem dan Perangkat Lunak (Software Design and System)

Dalam tahapan ini akan dibentuk suatu arsitektur sistem berdasarkan persyaratan yang telah ditetapkan. Dan juga mengidentifikasi dan menggambarkan abstarksi dasar sistem perangkat lunak dan hubunganhubungannya.

3. Implementasi dan Testing Unit (Implementation and Unit Testing)

Dalam tahapan ini, hasil dari desain perangkat lunak akan direalisasikan sebagai satu set program atau unit program. Setiap unit akan diuji apakah sudah memenuhi spesifikasinya.

4. Integrasi dan Testing Sistem (Integration and System Testing)

Dalam tahapan ini, setiap unit program akan diintegrasi satu sama lain dan diuji sebagai satu sistem yang utuh untuk memastikan sistem sudah memenuhi persyaratan yang ada. Setelah itu sistem akan dikirim ke pengguna sistem.

5. Operasional dan Pemeliharaan (Operation and Maintenance)

Dalam tahapan ini, sistem diinstal dan mulai digunakan. Selain itu juga memperbaiki error yang tidak ditemukan pada tahap pembuatan. Dalam tahap ini juga dilakukan pengembangan sistem seperti penambahan fitur dan fungsi baru[4].

\subsection{ERD (Entity Relationship Diagram)}

ERD adalah suatu diagram untuk menggambarkan desain konseptual dari model konseptual suatu basis data relasional. ERD juga merupakan gambaran yang menghubungkan antara objek satu dengan objek lain dalam dunia nyata [5].

\subsection{UML(United Modelling languange $)$}

UML (Unified Modeling Language) adalah bahasa pemodelan untuk sistem atau perangkat lunak yang berparadigma (berorientasi objek). Pemodelan (modeling) sesungguhnya digunakan untuk penyederhanaan permasalahan-permasalahan yang kompleks sedemikian rupa sehingga lebih mudah dipelajari dan dipahami [6]. 


\subsection{Metode Penelitian}

Metode pengumpulan data yang digunakan yaitu: metode observasi, metode wawancara dan metode studi pustaka.

Beberapa tahap yang dilakukan dalam analisa penelitian yang dibuat antara lain:

1. Analisis Kebutuhan Sistem

Dalam tahap ini penulis melakukan analisis mendalam tahapan sistem yang sedang berjalan saat ini, sehingga penulis bisa memahami dengan baik proses yang terjadi. Sehingga akan mempermudah penulis didalam membuat sistem informasi persediaan barang di PT. Pamindo Tiga T.

2. Desain Sistem dan Perangkat Lunak (Software Design and System)

Sistem informasi persediaan barang berbasis web dibangun dengan menggunakan bahasa pemrograman web PHP serta database MySQL dan desain sistem dibuat menggunakan UML (Use Case Diagram, Activity Diagram, Component Diangram, dan Deployment Diagram) sedangkan ERD (Entity Relationship Diagram) untuk menggambarkan hubungan antar data.

3. Implementasi dan Testing Unit (Implementation and Unit Testing)

Penulisan kode program merupakan tahap penerjemahan desain sistem yang telah dibuat ke dalam bentuk perintah-perintah yang dimengerti komputer. Pada perancangan program ini penulis membuat pemograman terstruktur dengan menggunakan bahasa pemograman PHP.

4. Integrasi dan Testing Sistem (Integration and System Testing)

Pengujian software dilakukan untuk memastikan bahwa software yang dibuat telah sesuai dengan desainnya dan semua fungsi dapat dipergunakan dengan baik tanpa ada kesalahan. Dalam tahap ini, perusahaan harus memastikan bahwa kerangka pengujian software dibuat dengan lengkap meliputi semua proses. Kebutuhan dan pengendalian yang ada di dalam dokumen analisa kebutuhan dan desain sistem. Pengujian dilakukan dengan metode black-box testing dan dilakukan pada saat akhir.

5. Operasional dan Pemeliharaan (Operation and Maintenance)

Pada tahapan ini penulis melakukan beberapa hal yang dapat mendukung agar program yang telah dibuat dapat digunakan secara maksimal yaitu dengan cara mendokumentasikan semua informasi tentang program dan melakukan pemeliharaan terhadap program yang telah dibuat.

\section{ANALISA DAN PEMBAHASAN}

\subsection{Proses Bisnis Sistem}

Prosedur atau proses bisnis sistem yang berjalan pada PT. Pamindo Tiga T dalam sistem persediaan barang ini yaitu pemohon meminta barang atau material yang hendak digunakan ke Bagian Procurement dengan memberikan for request sheet dan Bagain Procurement mengecek terlebih dahulu apakah barang yang diminta stoknya tersedia atau tidak, jika tersedia maka barang atau materialnya diberikan kepada Pemohon atau Pemakai, jika stok barang tidak tersedia maka bagian Procurement langsung membuatkan PO dan bagian Procurement memberikan Surat Jalan dan barang kepada Supplier. Setelah barang diterima dari supplier maka Bagian Gudang mencatat barang masuk tersebut kemudian baru memberikan barang atau material tersebut ke Pemohon atau Pemakai.

Setelah ada barang yang masuk dan keluar Bagian Procurement harus membuatkan laporan stok barang kepada Manager.

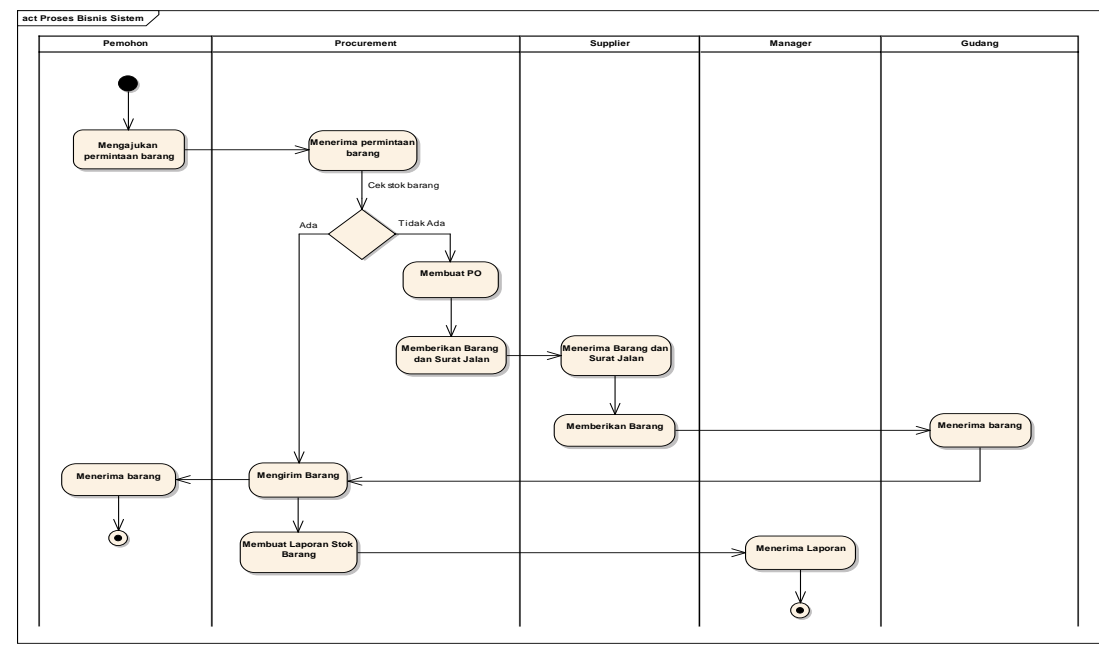

Gambar 2.Proses Bisnis Sistem 


\subsection{Tahanpan Analisis}

Pada sistem ini dibuat untuk mempermudah bagian Procurement dan bagian lainnya yang bersangkutan seperti bagian produksi dan Manajer Operasional dalam mengelola persediaan barang yang ada digudang.

Berikut analisa kebutuhan pengguna yaitu:

1. Analisa Kebutuhan Admin

a. Admin dapat mengelola data Master(User, Supplier, Barang)

b. Admin dapat mengelola data PO

c. Admin dapat melihat laporan barang dan laporan supplier

d. Admin dapat mengganti Password

2. Analisa Kebutuhan Bagian Gudang

a. Bagian Gudang dapat mengelola barang masuk dan barang keluar.

b. Bagian Gudang dapat melihat stok barang, laporan barang masuk dan barang keluar.

c. Bagain Gudang dapat mengganti password

3. Analisa Kebutuhan Bagian Procurement

a. Bagian Procurement dapat mengelola data barang dan data supplier.

b. Bagian Procurement dapat membuat PO (Purchase Order)

c. Bagian Procurement dapat mengganti password

4. Analisa Kebutuhan Bagian Manager

Bagian Manager dapat melihat laporan data barang, laporan barang masuk dan laporan barang keluar.

\subsection{Use case}

Use Case Diagram Sistem Informasi Persediaan Barang ini terbagi menjadi 4 bagian, yaitu:

1. Use Case Diagram Bagian Admin

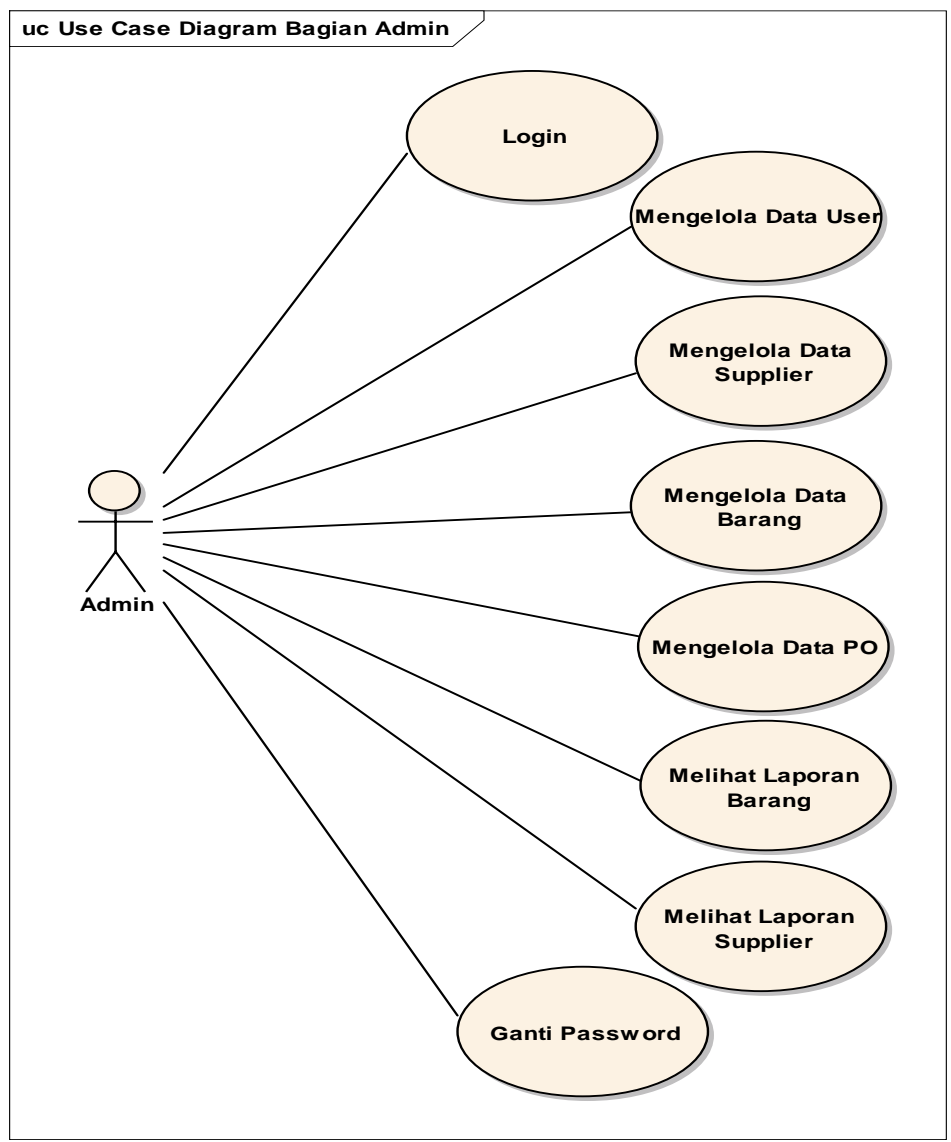

Gambar 3. Use Case Diagram Bagian Admin 
MEDIA INFORMATIKA BUDIDARMA, Vol 2, No 2, April 2018

ISSN 2614-5278 (media cetak)

ISSN 2548-8368 (media online)

Hal 1-9

2. Use Case Diagram Bagian Gudang

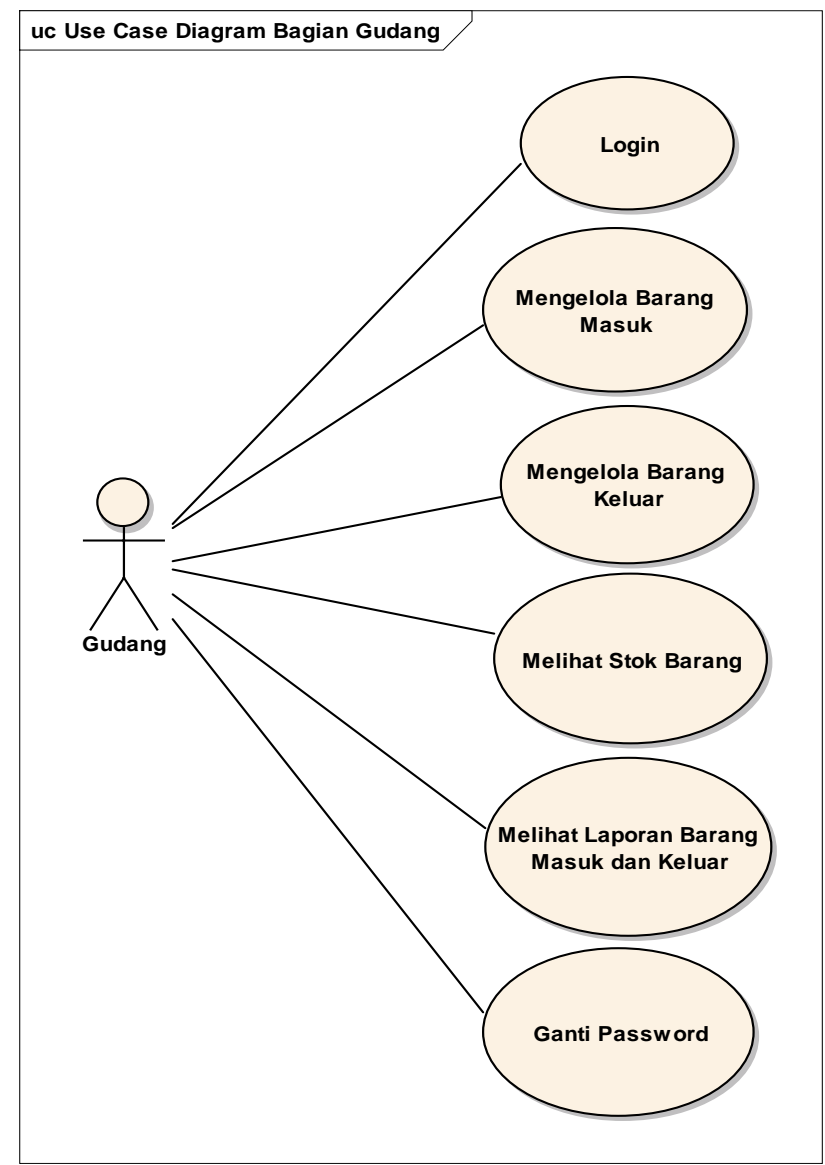

Gambar 4. Use case Diagram Bagian Gudang

3. Use Case Diagram Bagian Procurement

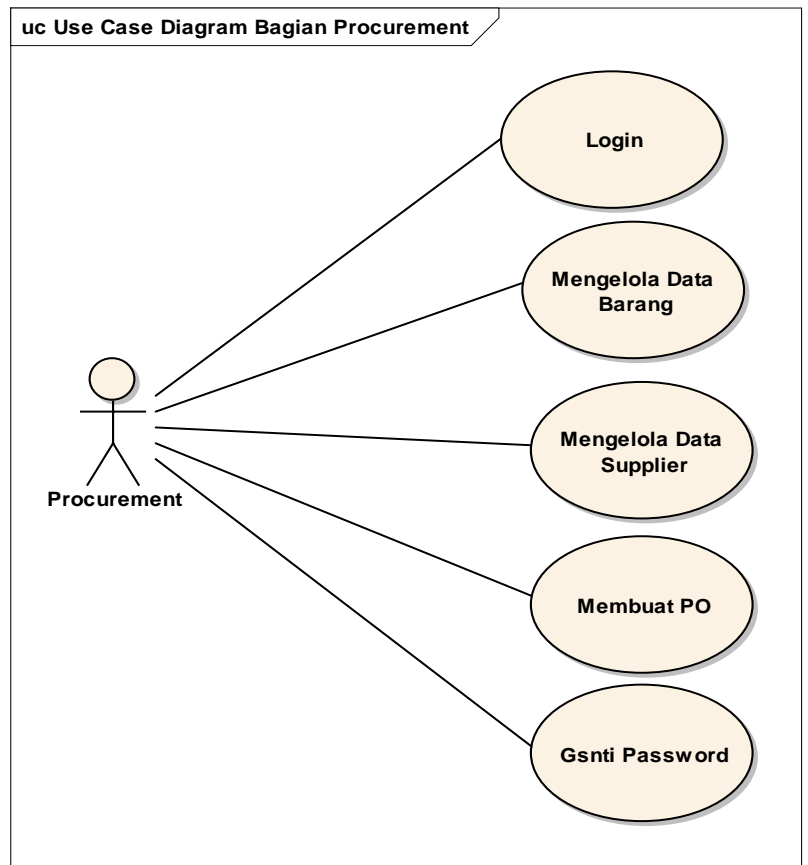

Gambar 5. Use case Diagram Bagian Procurement

Fatmawati | http://ejurnal.stmik-budidarma.ac.id/index.php/mib | Page | 5 
MEDIA INFORMATIKA BUDIDARMA, Vol 2, No 2, April 2018

ISSN 2614-5278 (media cetak)

ISSN 2548-8368 (media online)

Hal 1-9

4. Use Case Diagram Bagian Manager

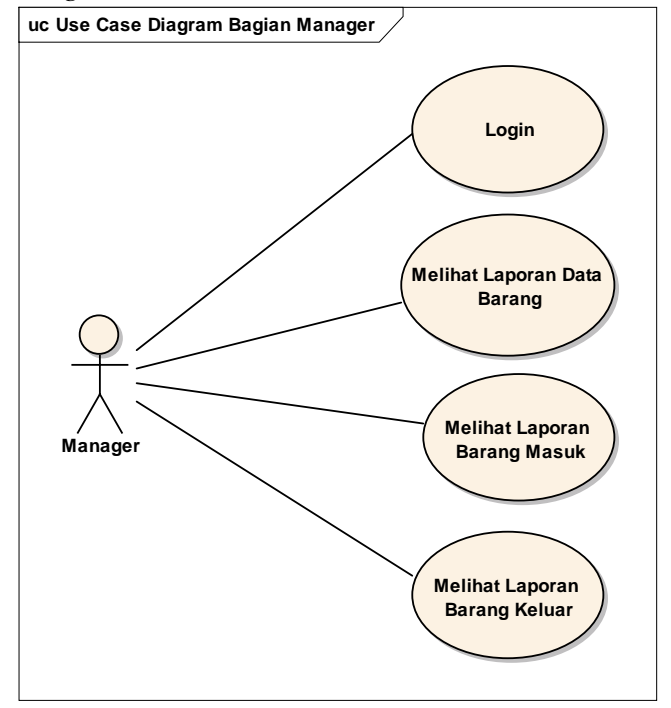

Gambar 6. Use case Diagram Bagian Manager

\subsection{Component Diagram}

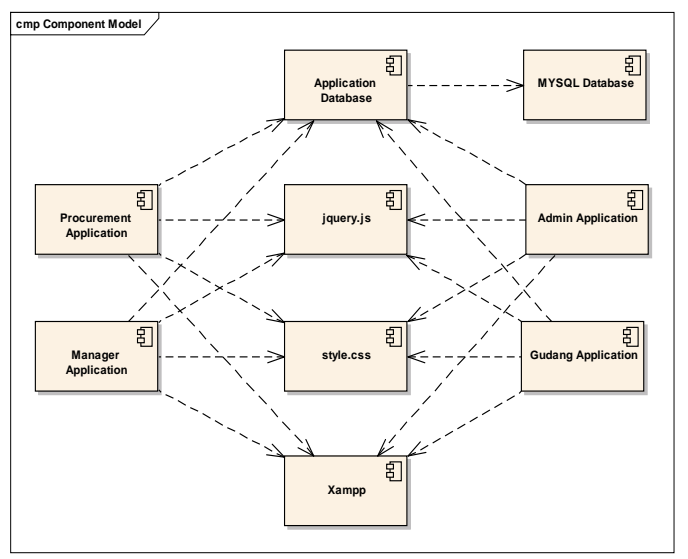

Gambar 7. ComponentDiagram Sistem Informasi Persediaan Barang

\subsection{Deployment Diagram}

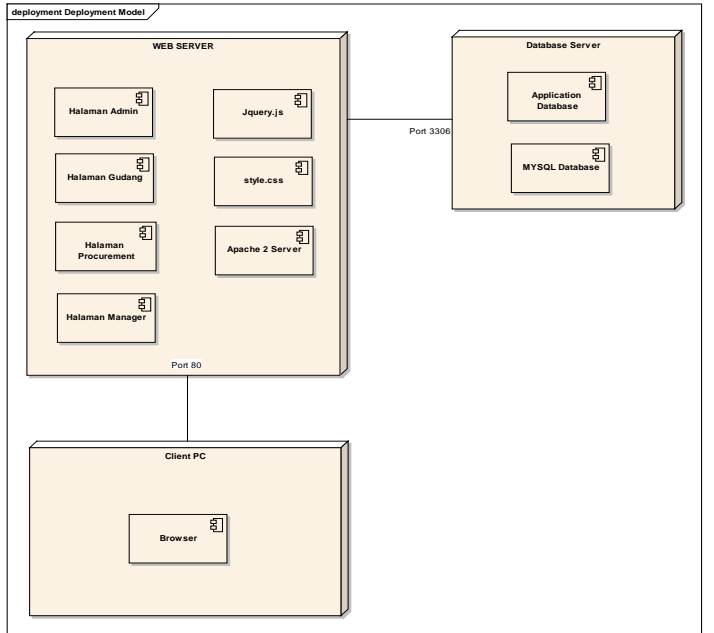

Gambar 8. Deployment Diagram Sistem Informasi Persediaan Barang

Fatmawati | http://ejurnal.stmik-budidarma.ac.id/index.php/mib | Page | 6 


\subsection{Desain Database}

Entity Relationship Diagram menjelaskan hubungan antar data dalam basis data yang terdiri dari objek-objek dasar yang mempunyai hubungan atau relasi antar objek-objek tersebut. Desain database dalam penelitian ini ditunjukkan pada gambar 9.

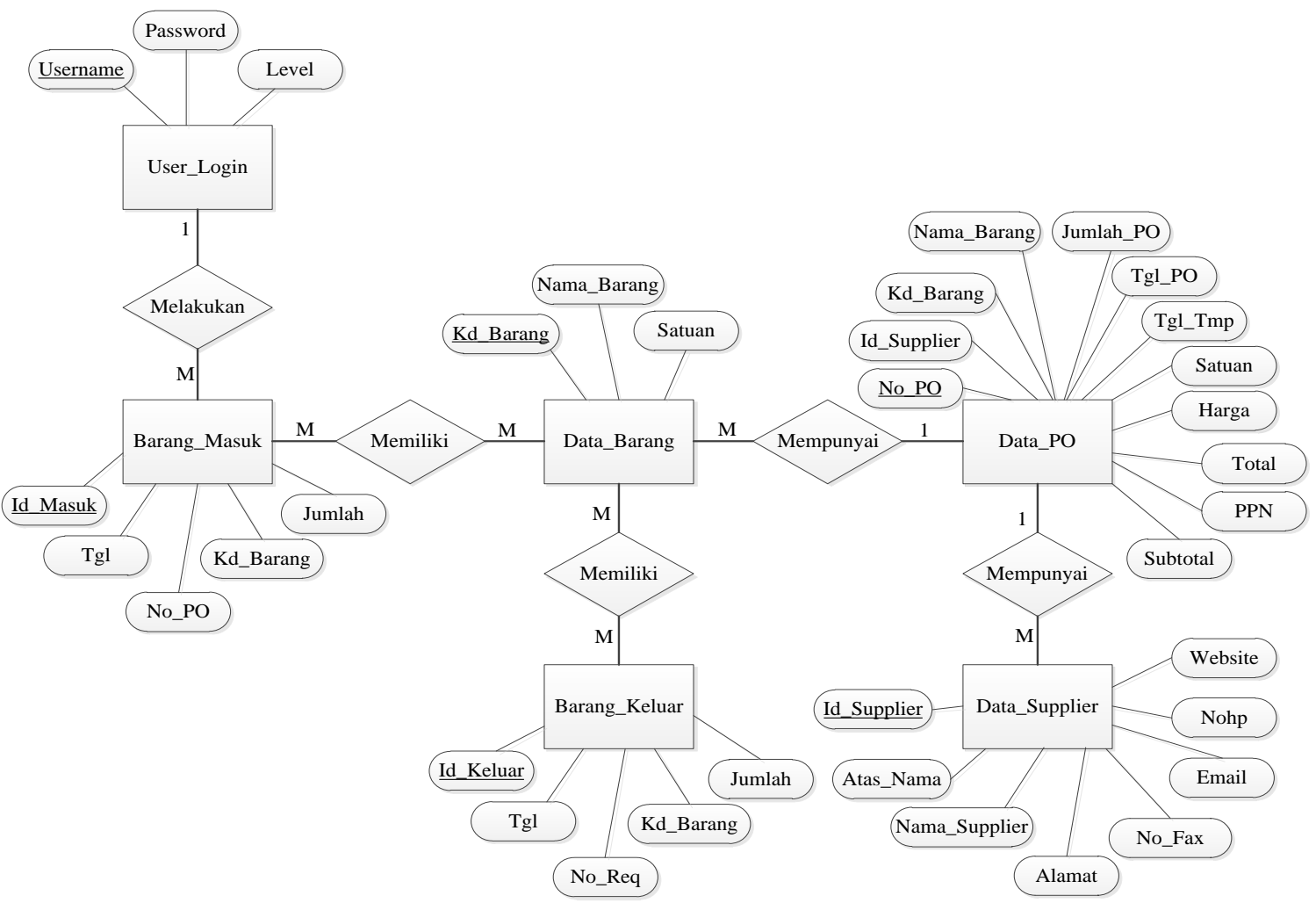

Gambar 9. Entity Relation Diagram (ERD)

\subsection{Tampilan Program}

1. Tampilan Sistem Informasi Persediaan

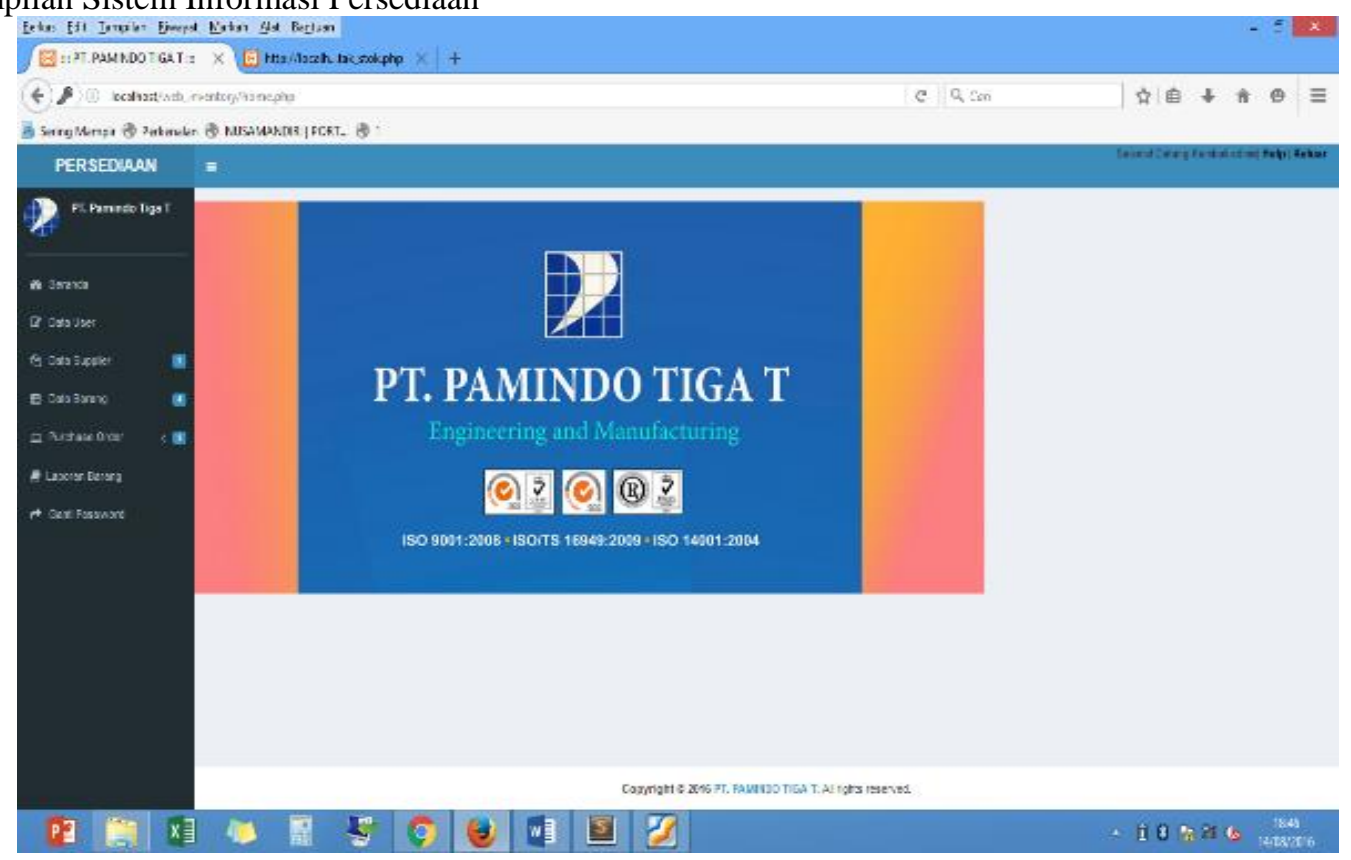

Gambar 10. Tampilan Sistem Informasi Persediaan

Fatmawati | http://ejurnal.stmik-budidarma.ac.id/index.php/mib | Page | 7 
2. Tampilan Input Barang Masuk

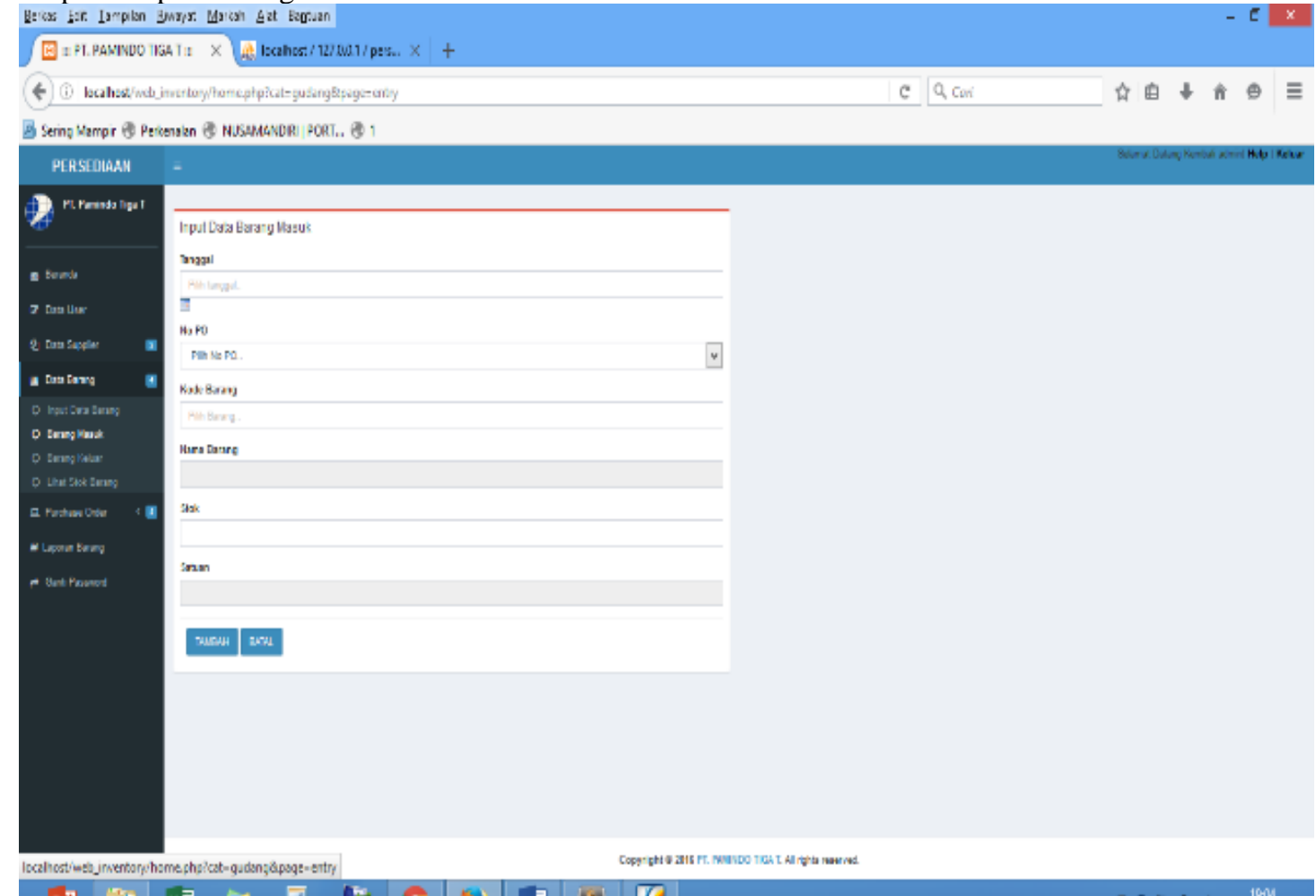

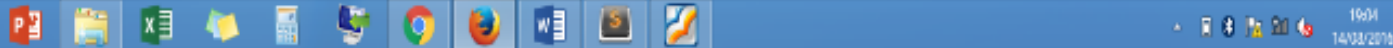

Gambar 11. Tampilan Input Barang Masuk

3. Tampilan Input Barang Keluar

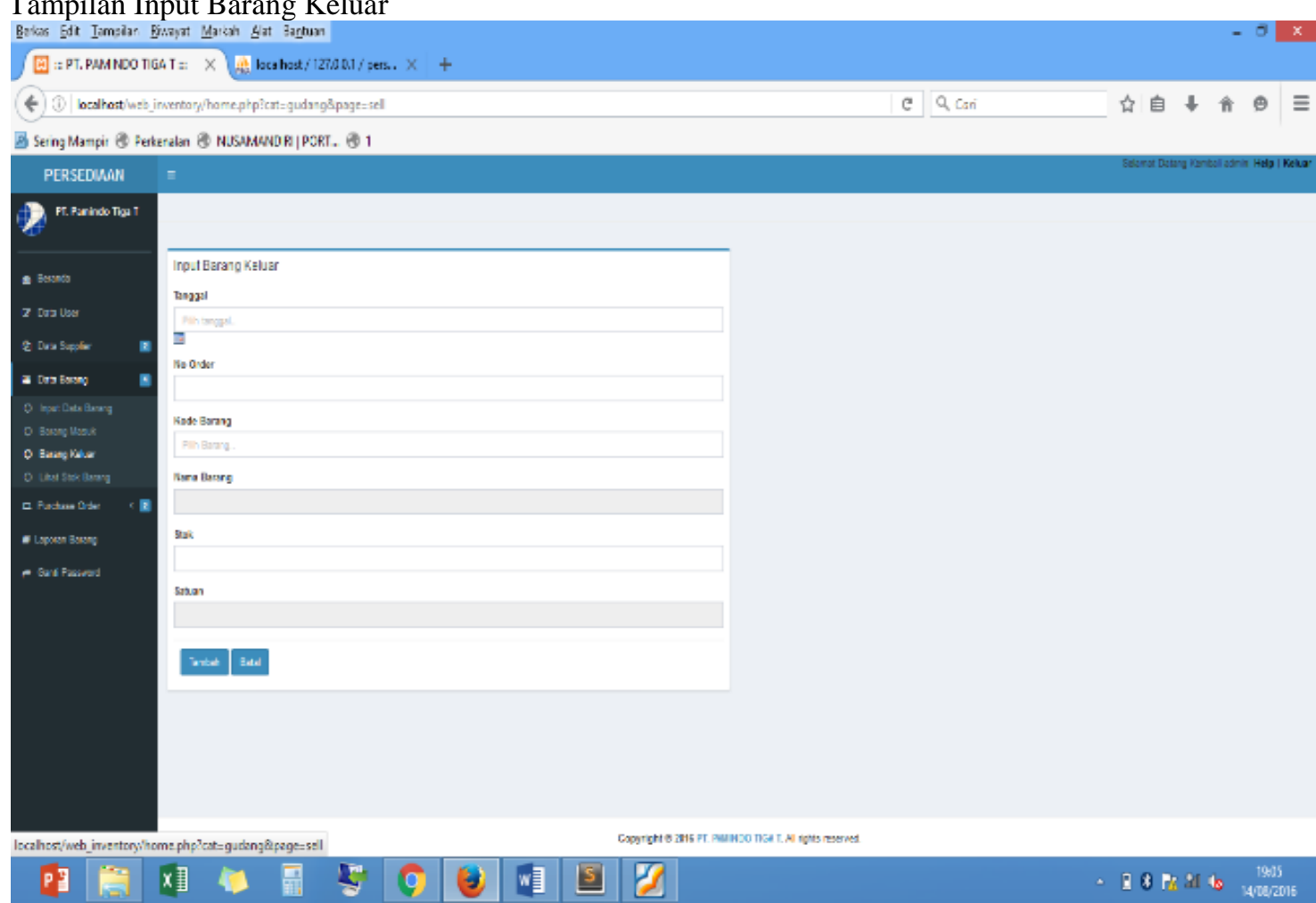

Gambar 12. Tampilan Input Barang Keluar

Fatmawati | http://ejurnal.stmik-budidarma.ac.id/index.php/mib | Page | 8 
4. Tampilan Stok Barang

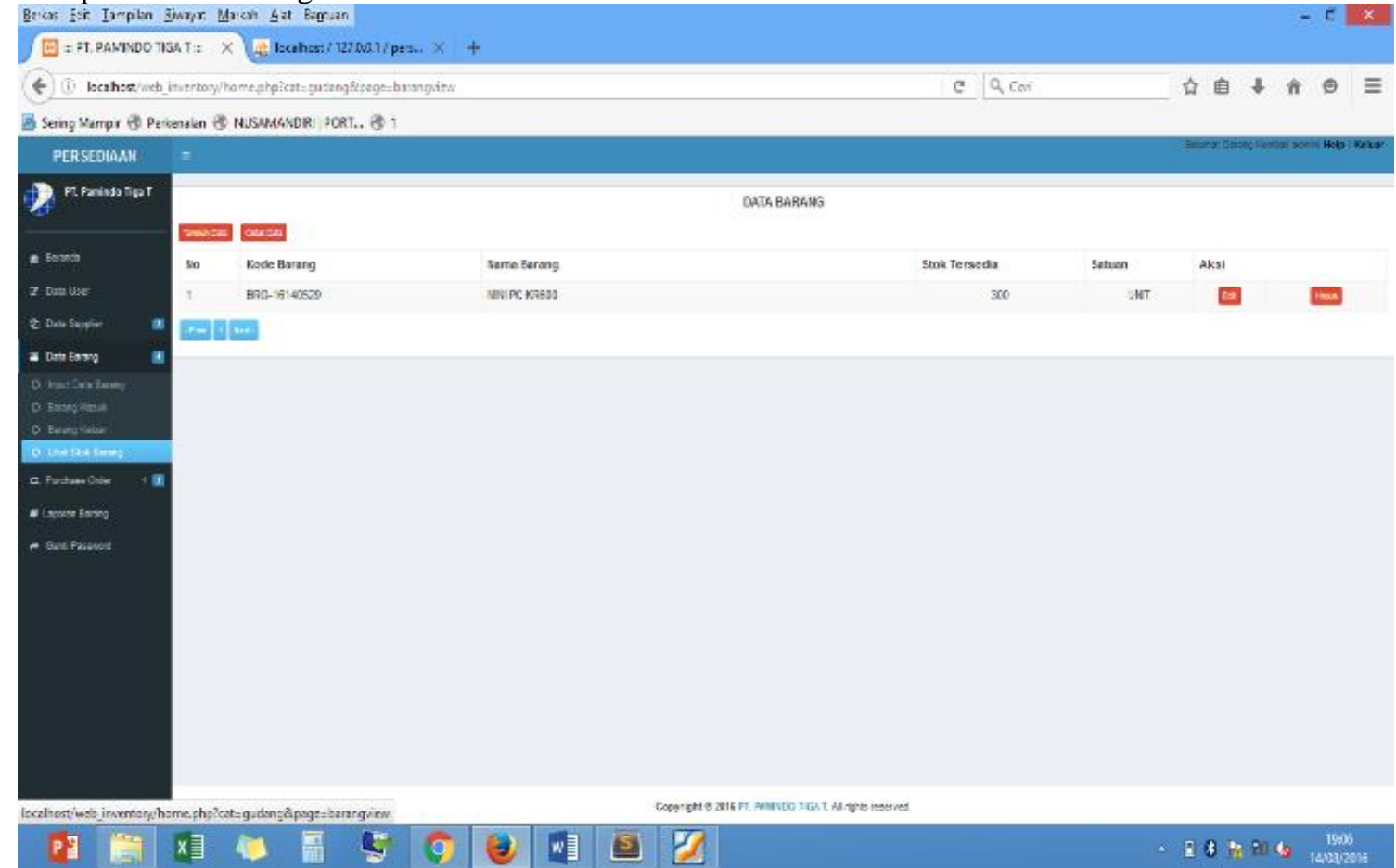

Gambar 13 Tampilan Stok Barang

\section{KESIMPULAN}

Dari hasil penelitian penulis menarik beberapa kesimpulan, yaitu:

1. Aplikasi sistem informasi persediaan barang pada PT. Pamindo Tiga T dapat mempermudah user dalam proses pengolahan barang masuk dan barang keluar.

2. Mengurangi resiko kesalahan dalam proses penginputan data.

3. Mempermudah dalam pencarian data barang.

\section{REFERENCES}

[1] Heryanto, Agus, Hilmi Fuad, Dani Dananggi. 2014. Rancang Bangun Sistem Informasi Inventory Barang Berbasis Web Studi Kasus di PT. Infinetworks Global Jakarta. ISSN: 2008-1672 Vol. 4 No.2/ September 2014. Jakarta, Jurnal Sisfotek Global Diambil dari : http:// journal.stmikglobal.ac.id/index.php/sisfotek8/article/view/18. (28 April 2016).

[2] Yakub. 2012. Pengantar Sistem Informasi. Yogyakarta: Graha Ilmu.

[3] Ristono, A. 2009. Manajemen Persediaan Edisi 1. Yogyakarta: Graha Ilmu.

[4] Sommerville, Ian. 2011. Software Engineering, Ninth Edition. Boston: Addison Wesley.

[5] Utami, Ema dan Hartanto. 2012. System Basis Data Menggunakan Microsoft SQL Server. Yogyakarta: Andi.

[6] Nugroho, A. 2010. Rekayasa Perangkat Lunak Menggunakan UML dan Java. Yogyakarta: Penerbit Andi.

[7] Yuhefizar. 2008. 10 Jam Menguasai Internet dan Teknologi Aplikasinya. Jakarta: PT.Elek Media Komputindo. 